\title{
BMJ Open Analgesic effects of intravenous ketamine after spinal anaesthesia for non-elective caesarean delivery: a randomised controlled trial
}

\author{
Prahlad Adhikari, ${ }^{1}$ Asish Subedi (1) ${ }^{2}$ Birendra Prasad Sah, ${ }^{2}$ Krishna Pokharel ${ }^{2}$
}

To cite: Adhikari P, Subedi A, Sah BP, et al. Analgesic effects of intravenous ketamine after spinal anaesthesia for non-elective caesarean delivery: a randomised controlled trial. BMJ Open 2021;11:e044168. doi:10.1136/ bmjopen-2020-044168

- Prepublication history for this paper is available online. To view these files, please visit the journal online (http://dx.doi. org/10.1136/bmjopen-2020044168).

Received 25 August 2020 Accepted 02 June 2021
Check for updates

(C) Author(s) (or their employer(s)) 2021. Re-use permitted under CC BY-NC. No commercial re-use. See rights and permissions. Published by BMJ.

${ }^{1}$ Anesthesiology, Narayani Subregional Hospital, Birgunj, Nepal ${ }^{2}$ Anesthesiology \& Critical Care, BP Koirala Institute of Health Sciences, Dharan, Nepal

Correspondence to Dr Asish Subedi; asish_subedi@alumni.harvard. edu

\section{ABSTRACT}

Objectives This study aimed to determine if low dose intravenous ketamine is effective in reducing opioid use and pain after non-elective caesarean delivery.

Design Prospective, randomised, double-blind. Setting Tertiary hospital, Bisheshwar Prasad Koirala Institute of Health Sciences, Dharan, Nepal

Participants 80 patients undergoing non-elective caesarean section with spinal anaesthesia.

Interventions Patients were allocated in 1:1 ratio to receive either intravenous ketamine $0.25 \mathrm{mg} / \mathrm{kg}$ or normal saline before the skin incision.

Primary and secondary outcome measures The primary outcome was the total amount of morphine equivalents needed up to postoperative 24 hours. Secondary outcome measures were postoperative pain scores, time to the first perception of pain, maternal adverse effects (nausea, vomiting, hypotension, shivering, diplopia, nystagmus, hallucination) and neonatal Apgar score at 1 and $5 \mathrm{~min}$, neonatal respiratory depression and neonatal intensive-care referral.

Results The median (range) cumulative morphine consumption during the first 24 hours of surgery was 0 $(0-4.67) \mathrm{mg}$ in ketamine group and $1(0-6) \mathrm{mg}$ in saline group ( $p=0.003)$. The median (range) time to the first perception of pain was $6(1-12)$ hours and $2(0.5-6)$ hours in ketamine and saline group, respectively $(p<0.001)$. A significant reduction in postoperative pain scores was observed only at 2 hours and 6 hours in the ketamine group compared with placebo group $(p<0.05)$. Maternal adverse effects and neonatal outcomes were comparable between the two groups.

Conclusions Intravenous administration of low dose ketamine before surgical incision significantly reduced the opioid requirement in the first 24 hours in patients undergoing non-elective caesarean delivery. Trial registration number NCT03450499.

\section{INTRODUCTION}

Effective analgesia following caesarean delivery (CD) is important as it enhances maternal recovery, reduces the risk of deep vein thrombosis and facilitates the mother's ability to care for her baby. ${ }^{1}$ In recent years, both pharmacological and nonpharmacological modalities for postcaesarean

\section{Strengths and limitations of this study}

- The nature of the study design (randomised control trial) allows a causal inference that is, whether preincisional administration ketamine during caesarean delivery has opioid sparing effect.

- Due to the small sample size the findings cannot be generalised.

- The end point of the study was also limited to postoperative 24 hours only.

analgesia have been extensively studied; yet, none of them are able to provide optimum postoperative analgesia. ${ }^{2}$ Importantly, multimodal analgesia provides superior analgesia with fewer adverse effects related to opioids, and therefore, use of non-opioid analgesic in alleviating postoperative pain is generally preferred. $^{2}$ In this regard, opioid-sparing drugs, such as ketamine may be valuable in providing better analgesia without major adverse effects. ${ }^{3}$

Both central and peripheral mechanisms have been postulated for ketamine, as it not only abolishes peripheral afferent noxious stimuli but also prevents central sensitisation. ${ }^{45}$ A recent meta-analysis demonstrated that perioperative administration of noncompetitive N-methyl-D-aspartate (NMDA) receptor antagonist ketamine reduces postoperative pain intensity and analgesic consumption. ${ }^{6}$

Non-opioid analgesia plays a vital role in providing good quality analgesia during CD. The effect of ketamine on postoperative pain following spinal anaesthesia in an elective CD has been investigated. ${ }^{78}$ However, its analgesic role in a non-elective $\mathrm{CD}$ have not been explored to date. In this study, we examined the effect of low-dose intravenous ketamine on opioid requirement as morphine equivalent and pain intensity (as measured by 
Numeric Rating Scale scores) following spinal anaesthesia for non-elective CD.

\section{METHODS}

This prospective, randomised, placebo-controlled, double-blind study was conducted at Bisheshwar Prasad Koirala Institute of Health Sciences (BPKIHS), Dharan, Nepal, between 2 April 2018 and 7 March 2019. The study was conducted according to the ethical principles reported in the Declaration of Helsinki and adheres to the Consolidated Standards of Reporting Trials statement.

Parturients at term undergoing non-elective, category 2 and 3 (according to National Institute for Health and Care Excellence guideline classification of urgency of emergency caesarean), ${ }^{9}$ lower segment $\mathrm{CD}$ under spinal anaesthesia with American Society of Anaesthesiologists physical status II were eligible for this trial. Women with body mass index $\geq 40 \mathrm{~kg} / \mathrm{m}^{2}$, height $<150 \mathrm{~cm}$, current use of pain medication including opioids, history of substance abuse or hallucinations, cardiovascular disease, diabetes, multiple gestations, known fetal abnormality, chronic pain were excluded. Other exclusion criteria were contraindications to the spinal anaesthesia, severely compromised fetus requiring general anaesthesia and those patients who received labour analgesia.

Independent anaesthesia supporting staff randomly assigned the patients in a 1:1 ratio to receive either ketamine or normal saline using a computer-generated simple random sequence. The patient allocation was concealed in sealed opaque envelopes marked with the study identification number. The anaesthesia assistant who was not involved in the study opened the concealed envelope and prepared the study drug in a syringe according to the group allocation and labelled it. The study subject and the investigators assessing the outcome were blinded to the group assignment. Group KET received intravenous ketamine (Ketamax, Troikaa Pharmaceuticals, Gujarat, India) $0.25 \mathrm{mg} / \mathrm{kg}$ and group NS received $0.9 \%$ normal saline.

A total of 80 (40 in each group) patients was enrolled. Each eligible patient was informed about the nature of the study in the labour room or emergency ward once the decision was made regarding CD. Subsequently, written informed consent was obtained, and a preanaesthetic check-up was done. During this visit, patients were also educated on the use of a $10 \mathrm{~cm}$ Numeric Rating Scale (NRS), with 0 representing no pain and 10 representing the worst imaginable pain. All patients received intravenous metoclopramide $10 \mathrm{mg}$ and ranitidine $50 \mathrm{mg}$ for aspiration prophylaxis. Patients were transferred to the operating room and standard monitoring was applied. An infusion of Lactated Ringer's (RL) solution was initiated at a minimal rate via18-gauge intravenous cannula placed on the forearm.

With the patient in an appropriate position, a 25 gauge Quincke needle was inserted at L3-4 or L4-5 interspace; and intrathecal (IT) $2.2 \mathrm{~mL}$ of $0.5 \%$ heavy bupivacaine with $10 \mu \mathrm{g}$ fentanyl was administered. An anaesthesiologist who was unaware of the study group injected the spinal drug. RL was administered at a rapid rate beginning at the time of the IT injection. After noting the time of injection, the patient was placed in a supine position with $15^{\circ}$ left tilt. The study drug, according to the allocated group, was injected intravenously just before the surgical incision. Oxygen was administered via the face mask at the rate of $5 \mathrm{~L} / \mathrm{min}$.

The onset of a sensory block was assessed using alcoholsoaked cotton swabs. Initially, every minute, the sensory block level was checked. When the sensory block reached the T6 level, surgery was started. Intraoperative pain was managed with fentanyl $20 \mu \mathrm{g}$ titrated to a maximum of $100 \mu \mathrm{g}$ by the attending anaesthesiologist. Intraoperative fall of systolic arterial pressure $>20 \%$ of the baseline or $<100 \mathrm{~mm} \mathrm{Hg}$ and heart rate (HR) $<50$ beats/min were considered significant. Hypotension was managed with increasing fluid administration (RL) rate and intravenous phenylephrine $50 \mu \mathrm{g}$ (if $\mathrm{HR}>50$ beats $/ \mathrm{min}$ ) or ephedrine $6 \mathrm{mg}$ (if $\mathrm{HR}<50$ beats / $\mathrm{min}$ ). Bradycardia (HR $<50$ beats/ $\mathrm{min}$ ) was managed with atropine $0.4 \mathrm{mg}$ intravenously. Time from the spinal injection to the delivery was noted. After the delivery of baby, 3 IU of oxytocin was administered intravenous over $\geq 30 \mathrm{~s}$, followed by an infusion of $10 \mathrm{IU} /$ hour (oxytocin $40 \mathrm{IU}$ in $500 \mathrm{~mL}$ of Hartmann's solution). Newborn Apgar score was noted at 1 and $5 \mathrm{~min}$ after birth. Both groups received $1 \mathrm{~g}$ intravenous paracetamol every 6 hours and $30 \mathrm{mg}$ IV ketorolac every 8 hours starting at the end of surgery.

Postoperative pain was evaluated using NRS at rest and on an attempt to move or bend forward from the bed. During the stay at the postanaesthesia care unit (PACU; On arrival, 1 and 2 hours thereafter), if NRS score was $>3$, the patient received IV fentanyl $15 \mu \mathrm{g}$, and it was repeated every 5 min until NRS was $\leq 3$. In the postoperative ward (6, 12, and 24 hours) intravenous morphine $2 \mathrm{mg}$ was administered for NRS score $>3$, and it was repeated until NRS $\leq$ 3.

The primary outcome was the total consumption of opioids as morphine equivalents up to 24 hours after surgery. Secondary outcomes were postoperative pain scores at rest and on movement; time to the first perception of pain (in hours); maternal adverse effects (incidence of nausea, vomiting, shivering, diplopia, nystagmus, hallucination); neonatal Apgar scores; neonates requiring resuscitation and intensive-care admission. Maternal adverse effects were noted intraoperatively and up to 24 hours after surgery. Presence of hallucination was based on a criterion of verbally reporting of sensory experiences with or without intuition and not triggered by a relevant stimulus. ${ }^{10}$ Nausea and vomiting were rated on a scale of $0-3$ (0, no nausea, no vomiting, 1 light nausea, no vomiting episodes, 2 moderate nausea, 1 or 2 vomiting episodes, 3 severe nausea, 3 or more vomiting episodes).${ }^{11}$ Intravenous ondansetron $4 \mathrm{mg}$ was given when the score was $\geq 2$. Shivering was graded using a scale described by Tsai and Chu. ${ }^{12}$ Pethidine $20 \mathrm{mg}$ was administered 
intravenously if shivering involved the whole body. The equivalent dose of fentanyl consumed (intraoperative and PACU) for pain and pethidine needed for shivering was converted to morphine from an online dose equivalent calculator (www.globalrph.com/medcalcs/ opioid-pain-management-converter-advanced).

\section{Statistical analysis}

The data collected in the case report form were entered in the Microsoft Excel 2016 software. All analyses were conducted using STATA software V.15 (Stata). Normality of the data was checked using histogram, KurtosisSkewness test and Shapiro-Wilk test. Parametric data were presented as mean $\pm \mathrm{SD}$ and non-parametric data as median (range). For the normally distributed data, Student' t-test and for the non-normally distributed data, Mann-Whitney $\mathrm{U}$ test were applied. The categorical data were compared using the $\chi^{2}$ test or Fisher exact test as appropriate. Post hoc analysis using the Bonforrini correction was applied for comparisons of postoperative pain scores between the two groups. For this, an adjustment of the alpha value was made as 0.05 divided by six-time points of assessment, that is, $0.05 / 6=0.008$.

\section{Sample size}

The sample size was calculated based on a previous study, ${ }^{13}$ which showed a mean \pm SD consumption of pethidine in the ketamine group as $54.17 \pm 12.86 \mathrm{mg}$ and $74.44 \pm 33.82 \mathrm{mg}$ in the placebo group. To detect this difference, assuming $\alpha=0.05$ and $\beta=0.1$ (90\% power) and using the two-tailed Student's t-test, 34 subjects were required in each group (STATA V.15, Stata). Finally, 40 patients were assigned to each group to allow for possible drop-outs.

\section{Patient and public involvement}

Patients or the public were not involved in the design, or conduct, or reporting, or dissemination plans of our research.

\section{RESULTS}

Among 92women eligible for the study, 80 were enrolled, as eight subjects did not meet the inclusion criteria and four refused to give consent. (figure 1) The demographic and clinical characteristics of both groups are demonstrated in table 1.

The median (range) 24 hours morphine equivalent required in KET group was 0 (0-4.67) $\mathrm{mg}$ compared with 1 (0-6) $\mathrm{mg}$ in NS group ( $\mathrm{p}=0.003$ ) (figure 2). Mean 24 hours morphine consumption were $0.53 \pm 1.22 \mathrm{mg}$ in the KET group and $1.58 \pm 1.87 \mathrm{mg}$ in the NS group (mean difference $-1.05 \mathrm{mg}, \mathrm{p}=0.004)$. In PACU, the median (range) dose of fentanyl consumed was $0(0-0) \mu \mathrm{g}$ in parturients receiving ketamine vs $0(0-20) \mu \mathrm{g}$ in those receiving normal saline $(\mathrm{p}=0.01)$. In the surgical unit, median morphine consumed was $0(0-4) \mathrm{mg}$ in the KET group and $0(0-4) \mathrm{mg}$ in the NS group $(\mathrm{p}=0.02)$. Significant differences between the two groups in terms of postoperative pain scores at rest were observed only at 2 hours and 6 hours (figure 3 ). Likewise, the pain scores during movement between the two groups were significant at 2 hours and 6 hours after surgery (figure 4). However, after adjustment for multiplicity $(\mathrm{p}=0.008)$, the difference in the pain scores after surgery between the two groups was only significant at 2 hours at rest and 2 hours and 6 hours during movement (figures 3 and $4)$. The median (range) time to the first perception of pain in the KET group was 6 (1-12) hours whereas in the NS group this period was reduced to $2(0.5-6)$ hours $(\mathrm{p}<0.001)$.

There were no significant differences in maternal adverse effects between the two groups (table 2). In the KET group, one patient complained of diplopia and one patient manifested nystagmus. There were no cases of hallucination in either group. Neonatal outcomes were comparable between the two groups (table 2). No neonatal deaths were observed.

Figure 1 Consort flow diagram of the study. 
Table 1 Comparison of patient demographic, block characteristics and surgical profiles

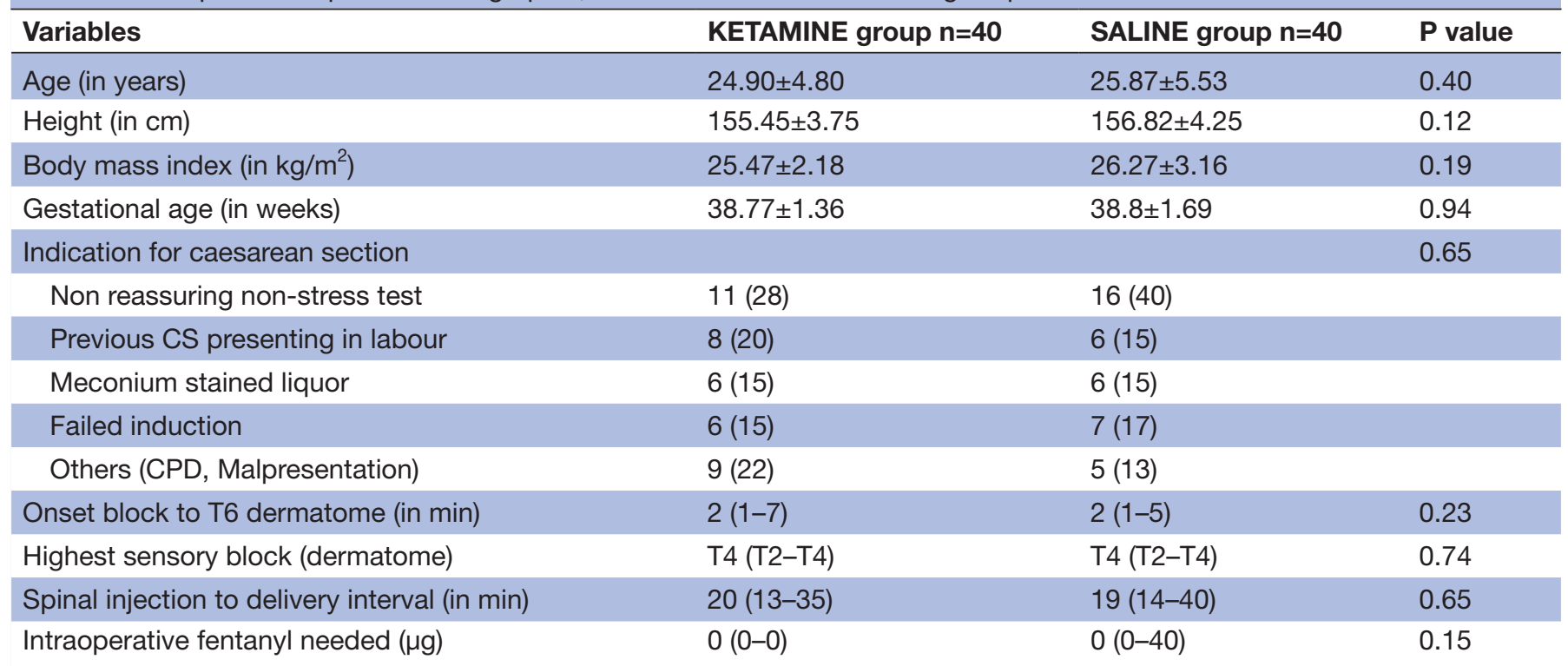

Values are expressed as mean \pm SD, number (\%) or median (range).

CPD, cephalopelvic disproportion; CS, Caesarean section.

\section{DISCUSSION}

Our study showed that preincisional intravenous low-dose ketamine reduced perioperative opioid requirement in patients undergoing non-elective CD under spinal anaesthesia as compared with the placebo. Lower pain scores were observed in the ketamine group as compared with the placebo at 2 and 6 hours postoperatively. In addition, the time to the first perception of pain was earlier in the normal saline group than the ketamine group.

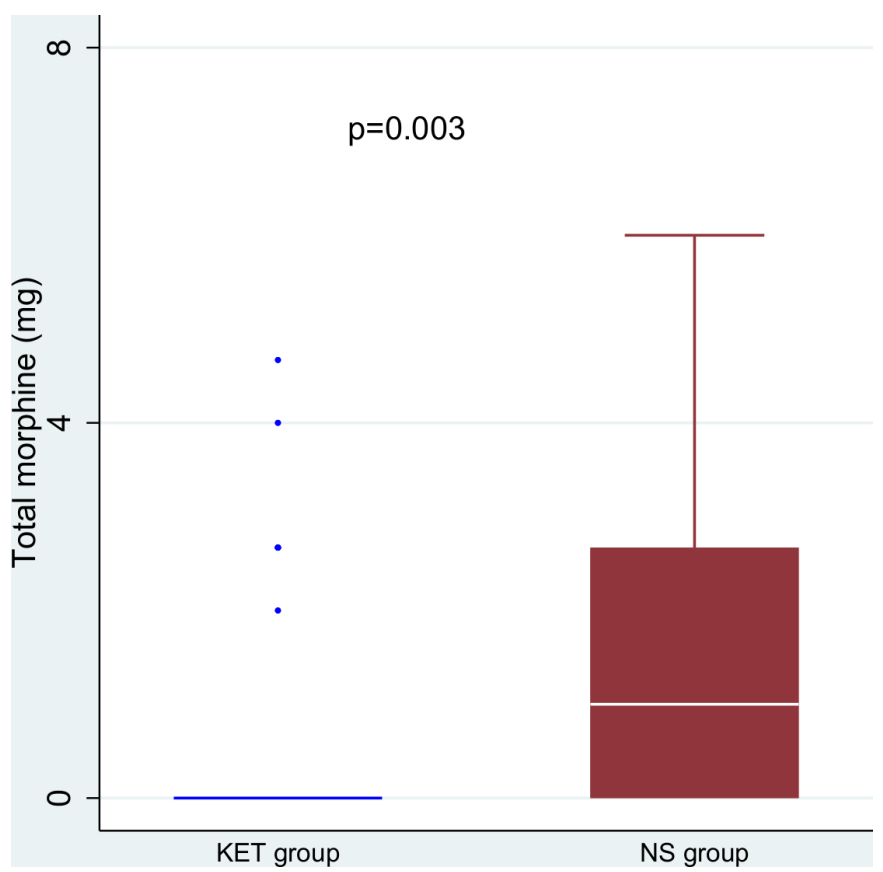

Figure 2 Total morphine equivalent for 24 hours postoperatively in patients receiving ketamine (KET group) and saline (NS group).
There is little evidence to suggest that there is any difference in postoperative pain intensity between the elective and non-elective CD. ${ }^{14}$ However, previous studies have shown that woman who had an emergency $\mathrm{CD}$ was more likely to encounter negative birth experience, high anxiety level and post-traumatic disorder than a woman who underwent elective CD. ${ }^{14-16}$ Because there is a significant link between psychological distress and pain after surgery, focus on good quality perioperative analgesia during the non-elective $\mathrm{CD}$ is also needed. Therefore, we tested the analgesic role

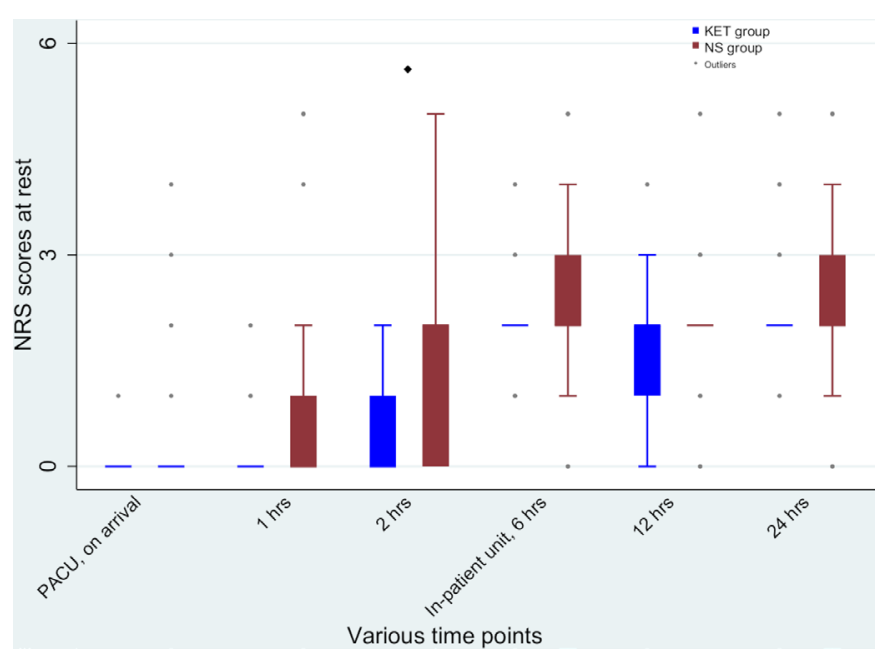

Figure 3 Postoperative Numerical Rating Scale (NRS) scores at various time points at rest. After adjustment for multiplicity significant difference between the groups was detected at 2 hours ( $p<0.05)$, PACU, postanaesthesia care unit. KET group received ketamine and NS group received normal saline. 


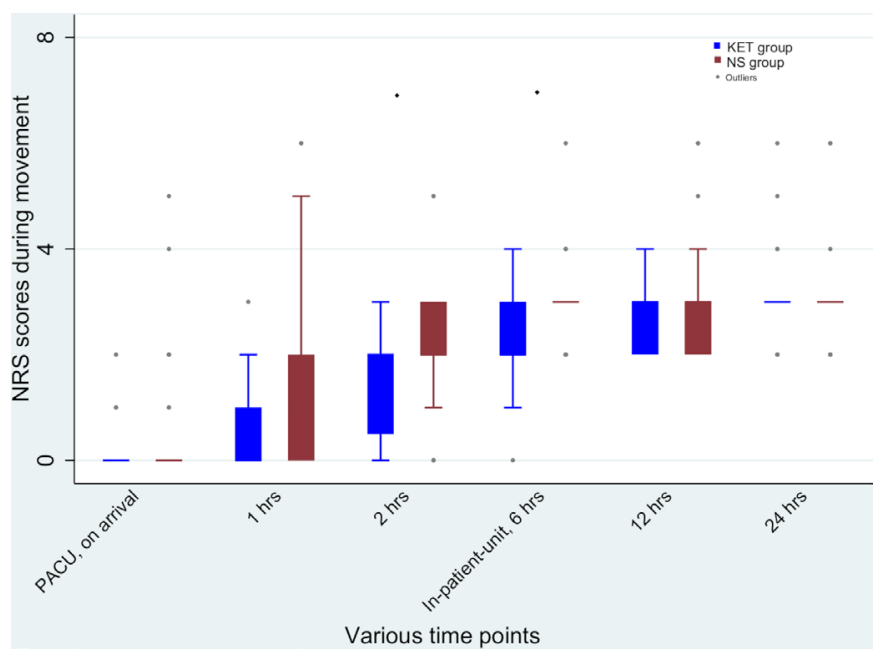

Figure 4 Postoperative Numerical Rating Scale (NRS) scores at various time points during movement. After adjustment for multiplicity significant difference between the groups was detected at 2 hours and 6 hours $\left({ }^{*} p<0.05\right)$, PACU, postanaesthesia care unit. KET group received ketamine and NS group received normal saline.

of ketamine in a non-elective $\mathrm{CD}$ because all previous studies were conducted in elective CD.

Opioids will continue to play an important role in perioperative pain management during $\mathrm{CD}$; but because of several unwanted effects associated with its use, nonopioid analgesics are generally added. ${ }^{17} 18$ Moreover, in resource-limited settings, longer-acting neuraxial opioids are less frequently used for post-CD analgesia because of their poor availability and lack of dedicated monitoring postoperatively. ${ }^{17}$ In this regard, opioid-sparing agents such as ketamine may prove to be beneficial. Though ketamine is widely used as an anaesthetic induction agent, in recent times, its role has widened. Among several new indications, perioperative administration of low-dose systemic ketamine has demonstrated analgesic properties. ${ }^{6}$

A subgroup study from a meta-analysis in 2015 that evaluated five trials performed under spinal anaesthesia for the elective CD found a significant reduction in cumulative morphine consumption with ketamine compared with the placebo group. ${ }^{19}$ However, high heterogeneity was observed among the studies, and this was probably due to variation in ketamine regimen. Two studies had used a preincisional single dose of $0.15 \mathrm{mg} / \mathrm{kg}$ ketamine and the other one had used a fixed dose of $30 \mathrm{mg}$, while the remaining two studies had continued the infusion of ketamine either until the end of surgery or up to 24 hours postoperatively. We administered a single dose of $0.25 \mathrm{mg} / \mathrm{kg}$ ketamine immediately after spinal injection because bolus dose up to $1 \mathrm{mg} / \mathrm{kg}$ intravenous is considered a subanaesthetic dose. ${ }^{20} \mathrm{~A}$ recent meta-analysis also supported this fact where more than $50 \%$ of the studies included in the analysis had used doses of ketamine boluses $\leq 1 \mathrm{mg} / \mathrm{kg}^{6}{ }^{6}$

We used intravenous ketamine before surgical incision, despite administration of spinal anaesthesia because pre-emptive administration of ketamine can block the development of central sensitisation in the postoperative period. Moreover, the analgesic effect is maximised when preincision ketamine is given in conjunction with other analgesics such as opioids and local anaesthetics pre-emptively. ${ }^{21}$ At a low bolus dose, ketamine produces analgesia by directly inhibiting NMDA receptors. ${ }^{20}$ Intravenous single dose of ketamine has an elimination halflife of $2-3$ hours, ${ }^{22}$ however, some traces of ketamine is still present 24 hours after injection. ${ }^{23}$ In addition, an active metabolite of ketamine (norketamine) which also produces analgesia has slow elimination compared with its parent compound.$^{2223}$ These are the likely reasons why a single dose of ketamine produces analgesia that may last beyond its elimination half-life.

Although we observed a statistically significant difference for the mean cumulative morphine requirement in the first 24 hours, it may be regarded as clinically insignificant because the mean difference was $1 \mathrm{mg}$. One reason for this small difference in overall opioid consumption and no significant change in pain intensity in late hours is likely due to the use of multimodal analgesia. In both the groups, we used intravenous paracetamol and ketorolac round the clock while an opioid was used as rescue analgesia. Unlike other studies where a single bolus dose of preincisional ketamine was administered, analgesics in the postoperative period were given only for breakthrough pain. ${ }^{813}$ As a result, in those studies, a larger

Table 2 Maternal adverse effects and neonatal outcomes

\begin{tabular}{llcc}
\hline & KETAMINE group $\mathbf{n = 4 0}$ & SALINE group $\mathbf{n = 4 0}$ & $\mathbf{P}$ value \\
\hline Hypotension & $13(32)$ & $16(40)$ & 0.48 \\
Nausea or vomiting & $4(10)$ & $5(12)$ & 0.72 \\
Shivering requiring pethidine & $5(12)$ & $8(20)$ & 0.36 \\
Apgar score 1 min & $8(6-8)$ & $8(6-8)$ & 0.54 \\
Apgar score 5 min & $9(7-9)$ & $9(8-9)$ & 0.67 \\
Resuscitation needed in neonate $(\mathrm{n})$ & $1(2 \%)$ & $1(2 \%)$ & 1.0 \\
Neonatal intensive care unit admission $(\mathrm{n})$ & $1(2 \%)$ & $2(5 \%)$ & 1.0 \\
\hline
\end{tabular}

Values are in median (range) and number (percentage). 
difference in total morphine equivalent consumption was observed that ranged from $2.11 \mathrm{mg}$ to $6.8 \mathrm{mg}$. In another study, contradict to our findings, low-dose ketamine did not offer any postoperative benefits despite using multimodal analgesia. ${ }^{7}$ In the above study, IT morphine was administered, and therefore, the prolonged analgesic effect of IT morphine could have overshadowed the analgesic effect of ketamine.

Several studies have explored the association between perioperative ketamine administration and postoperative nausea and vomiting (PONV). In patients with high risk for PONV undergoing lumbar spine surgery, ketamine increased the incidence of nausea. ${ }^{24}$ The emetogenic effect of ketamine is likely due to its inhibitory action on serotonin uptake at the synaptic terminal; however, the precise mechanism remains elusive. ${ }^{25}{ }^{26}$ Although we did not observe a significant change in the incidence of PONV, the role of ketamine for PONV during CD is still uncertain. While one study found a reduced incidence of intraoperative nausea and vomiting, another showed an increased frequency of vomiting. ${ }^{27} 28$ As a result, there are assumptions made for and against the role of ketamine on PONV: emetogenic versus opioid-sparing effects; whether a reduction in the frequency of hypotension indirectly minimises the PONV episodes. Because PONV following spinal anaesthesia is multifactorial, it is difficult to establish a causal relationship between ketamine and PONV. Nevertheless, large clinical trials are warranted before any conclusion can be drawn. Prophylactic use of low doses of ketamine is effective in preventing shivering post-spinal anaesthesia for $\mathrm{CD}^{29}$ Although we found fewer parturients from ketamine group required pethidine for shivering in comparison to normal saline group, the difference was not significant statistically. The reason for this observation could be that our study not powered enough to detect this difference.

Ketamine crosses the placenta rapidly and has a mean fetal-maternal ratio of 1.26 following an intravenous induction dose of anaesthesia. ${ }^{30}$ As a result, concern has been expressed as to whether or not ketamine administered in clinical doses at the time of delivery produces neurotoxic effects in newborns. Animal studies have shown the dose and exposure dependent effect of ketamine on the developing brain. A 5-hour ketamine infusion in pregnant rhesus female monkey produced neuronal apoptosis in the fetal brain. ${ }^{31}$ On the other hand, no serious complication was observed in lamb fetus after pregnant ewes were anaesthetised with $20 \mathrm{mg} / \mathrm{kg}$ of intravenous ketamine for $\mathrm{CD} .{ }^{32}$ Based on clinical studies, a meta-analysis on the role of intravenous ketamine in parturients undergoing CD demonstrated no differences in the Apgar scores of neonates between ketamine-treated and placebo group. ${ }^{19}$ Likewise, ketamine administered at $1 \mathrm{mg} / \mathrm{kg}$ intravenous in parturient did not worsen the newborn acid-base status in comparison to either thiopentone anaesthesia or placebo group. ${ }^{33}{ }^{34}$ We too observed no significant difference in neonatal outcomes between the two groups. As there is a paucity of data related to the neurodevelopmental effects in neonates after exposure to ketamine during $\mathrm{CD}$, it is wise not to exceed ketamine doses above $1.5 \mathrm{mg} / \mathrm{kg}$ intravenous, and infusions are probably best avoided.

There are several limitations. First, the endpoint of the study was limited to postoperative 24 hours only. Second, we did not assess patient satisfaction and quality of recovery postoperatively.

In conclusion, our findings indicate that administration of pre-incisional low dose ketamine during non-elective $\mathrm{CD}$ under spinal anaesthesia reduces perioperative overall opioid requirement and lowers the pain scores in the early hours after surgery.

Contributors PA: This author helped in study design, patient recruitment, data collection and writing up of the first draft of the paper. AS: This author helped in study design, pateint recruitment, analysis and interpretation of data, manuscript revision and final draft. BPS: This author helped in study design, data collection and manuscript revision. KP: This author helped in study design, patient recruitment and final draft.

Funding The authors have not declared a specific grant for this research from any funding agency in the public, commercial or not-for-profit sectors.

Competing interests None declared.

Patient and public involvement Patients and/or the public were not involved in the design, or conduct, or reporting, or dissemination plans of this research.

Patient consent for publication Obtained.

Ethics approval The study was approved by the Institutional Review Committee of BPKIHS (IRC \#1089/017). All participants gave informed consent before taking part in the study.

Provenance and peer review Not commissioned; externally peer reviewed.

Data availability statement Data are available on reasonable request.

Open access This is an open access article distributed in accordance with the Creative Commons Attribution Non Commercial (CC BY-NC 4.0) license, which permits others to distribute, remix, adapt, build upon this work non-commercially, and license their derivative works on different terms, provided the original work is properly cited, appropriate credit is given, any changes made indicated, and the use is non-commercial. See: http://creativecommons.org/licenses/by-nc/4.0/.

ORCID iD

Asish Subedi http://orcid.org/0000-0002-0471-8760

\section{REFERENCES}

1 Yost NP, Bloom SL, Sibley MK, et al. A hospital-sponsored quality improvement study of pain management after cesarean delivery. Am J Obstet Gynecol 2004;190:1341-6.

2 Kerai S, Saxena KN, Taneja B. Post-caesarean analgesia: what is new? Indian J Anaesth 2017;61:200-14.

3 Bell RF, Dahl JB, Moore RA, et al. Perioperative ketamine for acute postoperative pain. Cochrane Database Syst Rev 2006;1:CD004603.

4 Woolf CJ, Thompson SWN. The induction and maintenance of central sensitization is dependent on $\mathrm{N}$-methyl-d-aspartic acid receptor activation; implications for the treatment of post-injury pain hypersensitivity states. Pain 1991;44:293-9.

5 Pockett S. Spinal cord synaptic plasticity and chronic pain. Anesth Analg 1995;80:173-9.

6 Brinck EC, Tiippana E, Heesen M, et al. Perioperative intravenous ketamine for acute postoperative pain in adults. Cochrane Database Syst Rev 2018;12:CD012033.

7 Bauchat JR, Higgins N, Wojciechowski KG, et al. Low-dose ketamine with multimodal postcesarean delivery analgesia: a randomized controlled trial. Int J Obstet Anesth 2011;20:3-9.

8 Menkiti ID, Desalu I, Kushimo OT. Low-dose intravenous ketamine improves postoperative analgesia after caesarean delivery with spinal bupivacaine in African parturients. Int J Obstet Anesth 2012;21:217-21. 
9 Yentis SM, Richards NA. Classification of urgency of caesarean section. Obstet Gynaecol Reprod Med 2008;18:139-40.

10 Telles-Correia D, Moreira AL, Gonçalves JS. Hallucinations and related concepts-their conceptual background. Front Psychol 2015;6:991.

11 Callesen T, Schouenborg L, Nielsen D, et al. Combined epiduralspinal opioid-free anaesthesia and analgesia for hysterectomy. $\mathrm{Br} J$ Anaesth 1999;82:881-5.

12 Tsai YC, Chu KS. A comparison of tramadol, amitriptyline, and meperidine for postepidural anesthetic shivering in parturients. Anesth Analg 2001;93:1288-92.

13 Behdad S, Hajiesmaeili MR, Abbasi HR, et al. Analgesic effects of intravenous ketamine during spinal anesthesia in pregnant women undergone caesarean section; a randomized clinical trial. Anesth Pain Med 2013;3:230-3.

14 Karlström A, Engström-Olofsson R, Norbergh K-G, et al. Postoperative pain after cesarean birth affects breastfeeding and infant care. J Obstet Gynecol Neonatal Nurs 2007;36:430-40.

15 Gamble J, Creedy D. Psychological trauma symptoms of operative birth. Br J Midwifery 2005;13:218-24.

16 Bansal T, Joon A. A comparative study to assess preoperative anxiety in obstetric patients undergoing elective or emergency cesarean section. Anaesth Pain Intensive Care 2017;21:25-30.

17 Bishop DG, Gibbs MW, Dyer RA. Post-caesarean delivery analgesia in resource-limited settings: a narrative review. Int $J$ Obstet Anesth 2019;40:119-27.

18 Hamburger J, Beilin Y. Systemic adjunct analgesics for cesarean delivery: a narrative review. Int J Obstet Anesth 2019;40:101-18.

19 Heesen M, Böhmer J, Brinck ECV, et al. Intravenous ketamine during spinal and general anaesthesia for caesarean section: systematic review and meta-analysis. Acta Anaesthesiol Scand 2015;59:414-26.

20 Schmid RL, Sandler AN, Katz J. Use and efficacy of low-dose ketamine in the management of acute postoperative pain: a review of current techniques and outcomes. Pain 1999;82:111-25.

21 Wong CS, Lu CC, Cherng CH, et al. Pre-emptive analgesia with ketamine, morphine and epidural lidocaine prior to total knee replacement. Can J Anaesth 1997;44:31-7.

22 Mion G, Villevieille T. Ketamine pharmacology: an update (pharmacodynamics and molecular aspects, recent findings). CNS Neurosci Ther 2013;19:370-80.
23 Domino EF, Zsigmond EK, Domino LE, et al. Plasma levels of ketamine and two of its metabolites in surgical patients using a gas chromatographic mass fragmentographic assay. Anesth Analg 1982;61:87-92.

24 Song JW, Shim JK, Song Y, et al. Effect of ketamine as an adjunct to intravenous patient-controlled analgesia, in patients at high risk of postoperative nausea and vomiting undergoing lumbar spinal surgery. Br J Anaesth 2013;111:630-5.

25 Ghoneim MM, Hinrichs JV, Mewaldt SP, et al. Ketamine: behavioral effects of subanesthetic doses. J Clin Psychopharmacol $1985 ; 5: 70-7$

26 Martin DC, Watkins CA, Adams RJ, et al. Anesthetic effects on 5-hydroxytryptamine uptake by rat brain synaptosomes. Brain Res 1988;455:360-5.

27 Suppa E, Valente A, Catarci S, et al. A study of low-dose S-ketamine infusion as "preventive" pain treatment for cesarean section with spinal anesthesia: benefits and side effects. Minerva Anestesiol 2012;78:774-81.

28 Shabana AM, Nasr ES, Moawad HE. Effect of ketamine on intraoperative nausea and vomiting during elective caesarean section under spinal anaesthesia: a placebo-controlled prospective randomized double blinded study. Egypt J Anaesth 2012;28:169-74.

29 Liu J, Wang Y, Ma W. Shivering prevention and treatment during cesarean delivery under neuraxial anesthesia: a systematic review. Minerva Anestesiol 2018;84:1393-405.

30 Ellingson A, Haram K, Sagen N, et al. Transplacental passage of ketamine after intravenous administration. Acta Anaesthesiol Scand 1977;21:41-4.

31 Brambrink AM, Evers AS, Avidan MS, et al. Ketamine-induced neuroapoptosis in the fetal and neonatal rhesus macaque brain Anesthesiology 2012;116:372-84.

32 Musk GC, Netto JD, Maker GL, et al. Transplacental transfer of medetomidine and ketamine in pregnant ewes. Lab Anim 2012;46:46-50.

33 Nayar R, Sahajanand H. Does anesthetic induction for cesarean section with a combination of ketamine and thiopentone confer any benefits over thiopentone or ketamine alone? A prospective randomized study. Minerva Anestesiol 2009;75:185-90.

34 Maduska AL, Hajghassemali M. Arterial blood gases in mothers and infants during ketamine anesthesia for vaginal delivery. Anesth Analg 1978;57:121-3 